\section{Contribution of street food on dietary acrylamide exposure by youth aged nineteen to thirty in Perugia, Italy}

\author{
Maria Serena Altissimi, ${ }^{1}$ \\ Rossana Roila, ${ }^{2}$ Raffaella Branciari, ${ }^{2}$ \\ Dino Miraglia, ${ }^{2}$ David Ranucci, ${ }^{2}$ \\ Marisa Framboas, ${ }^{1}$ \\ Naceur Haouet ${ }^{1}$ \\ ${ }^{1}$ Institute for Experimental Veterinary \\ Medicine of Umbria and Marche, \\ Perugia; ${ }^{2}$ Department of Veterinary \\ Medicine, University of Perugia, \\ Perugia, Italy
}

\begin{abstract}
Acrylamide dietary intakes from selected street foods in youth population are estimated. The intake evaluation was carried out by combining levels of acrylamide in food, analytically determined by high performance liquid chromatography, with individual consumption data recorded using a questionnaire applied to a group of 200 students aged 19 to 30 . The mean value of acrylamide exposure was recorded to be $0.452 \mu \mathrm{g} / \mathrm{kg}$ bw/day, while the average intakes at $50^{\text {th }}$ and $95^{\text {th }}$ percentile were 0.350 $\mu \mathrm{g} / \mathrm{kg} \mathrm{bw} /$ day and $1.539 \mu \mathrm{g} / \mathrm{kg}$ bw/day, respectively. The street food categories that contributed the most to acrylamide intake are pizza and French fries. The margins of exposure, based on benchmark dose limits defined for neoplastic effects and peripheral neuropathy, are within the range of values that indicate a concern for public health as defined by European Authority for Food Safety (EFSA), confirming the needed effort to reduce acrylamide dietary exposure.
\end{abstract}

\section{Introduction}

The rise of fast food and street food vendors in western Countries pose several issues about this strategy for the local and global economy, about changing of life styles, but also on food safety for both microbiological and chemical point of view (Proietti et al., 2014). In this kind of food sector the use of baked and fried food is quite common and several papers highlights the possible formation of acrylamide (AA) and its metabolite glycidamide in these foods (EFSA, 2015, Tateo et al., 2007). Foods contributing the largest amount of acrylamide daily intake include baked cereal products, fried potatoes (French fries and chips) and coffee (Mesias and Morales, 2016, Pacetti et al., 2015), usually sold by street food vendors.

Acrylamide has been included in Group $2 \mathrm{~A}$ probably carcinogenic to humans by the International Agency for Research on Cancer (IARC 1994) and it is a concern to human health. In 2015 following a request from the European Commission, the European Food Safety Autority (EFSA) delivered a scientific opinion on acrylamide in food. Up to date, the data from human studies, both epidemiological and on biomarkers, are still inadequate for dose-response assessment therefore dose-response relationship has been set based on animal results. The experts have proposed two different $\mathrm{BMDL}_{10}$ (lower limit on the benchmark dose for a $10 \%$ response) for acrylamide: $0.17 \mathrm{mg} / \mathrm{kg}$ bw/day for neoplastic effects in mice and $0.34 \mathrm{mg} / \mathrm{kg}$ bw/day for peripheral neuropathy in rats. The margins of exposure (MOE) for the cancer-related effects of acrylamide, corresponding to the ratio between the $\mathrm{BMDL}_{10}$ and the dietary exposure of the population, range from 425 for average adult consumers down to 50 for high consuming toddlers, these ranges indicate a concern for public health (EFSA, 2015). Estimations of acrylamide exposure from diet are considered of utmost importance as no limits are set for foods, and exposure data, calculated for age groupings and gender, are the basis for a proper analysis of the exposure. Specific data could then be aggregated to estimate the national average level of exposure (Mills et al., 2009). The aims of this study were to evaluate the level of acrylamide in different food collected from street vendors in Perugia (Central Italy) and estimate the exposure for youth aged 19-30 considering their attitude towards street food and their frequency of consumption.

\section{Materials and Methods}

A survey was carried out from February to May 2015 to investigate individual food consumption data and to quantify acrylamide food intakes in a specific population. The survey was based on 200 subjects ( 81 male and 119 female) aged from 19 to 30 years. The subjects were asked to complete a questionnaire describing the type of street food consumed and frequency of consumption over a 7-day period. The participants were also asked to report weight and height (for dietary exposure calculation). All participants were students of the University of Perugia and young population living in Perugia recruited by street food vendors. The food categories selected for the
Correspondence: Raffaella Branciari, Department of Veterinary Medicine, University of Perugia, Via San Costanzo 4, 06126 Perugia (PG), Italy.

Tel: +39.075.5857932 - Fax: +39.075.5857932

E-mail: raffaella.branciari@unipg.it

Key words: Acrylamide exposure; MOE; Street Food; Young population.

Conflict of interest: the authors declare no potential conflict of interest.

Acknowledgments: this work is part of a research project funded by the Italian Ministry of Health (RC 005/12 - Esposizione all'acrilammide da parte del consumatore di prodotti RTE e valutazione di metodi di cottura per limitarne la formazione.

Received for publication: 5 July 2017

Revision received: 24 July 2017.

Accepted for publication: 28 July 2017.

This work is licensed under a Creative Commons Attribution-NonCommercial 4.0 International License (CC BY-NC 4.0).

(C) Copyright M.S. Altissimi et al., 2017

Licensee PAGEPress, Italy

Italian Journal of Food Safety 2017; 6:6881

doi:10.4081/ijfs.2017.6881

consumption assessment were 10 .

Different batches of selected street food were purchased in Perugia from street food vendors and analyzed for acrylamide using high-performance liquid chromatography (HPLC) method (Haouet et al., 2016). The acrylamide was extracted with water following the procedure of Haouet et al., 2016 and the extract was injected into a system consisting of an HPLC Shimadzu (Kyoto, Japan) instrument model RF-20AX consisting of a vacuum degasser, a quaternary pump, an auto-sampler, a thermostated column compartment and a diode array detector (DAD). The calibration standards and sample extracts were injected via a $10 \mu \mathrm{L}$ sample loop into a C18 RP column $(250 \times 4.6 \mathrm{~mm}$, Phenomenex Inc, Torrance, USA) thermostated at $25^{\circ} \mathrm{C}$. The detection wavelength was $238 \mathrm{~nm}$. A mixture of acetronitrile and acetic acid $(1.0 \mathrm{~g} / \mathrm{L}$ water solution) $(20: 80 \mathrm{v} / \mathrm{v})$ was used as the mobile phase. Peaks in the chromatograms were identified by comparing the retention time and UV spectrum with standard solutions of acrylamide (AA 99\% standards -SIGMAFluka St. Louis, MO, USA). The limit of detection (LOD) and limit of quantification (LOQ) were $20 \mu \mathrm{g} / \mathrm{kg}$ and $60 \mu \mathrm{g} / \mathrm{kg}$, respectively (Haouet et al., 2016).

For the dietary exposure evaluation (DE) of the selected population, individual consumption data were combined with the value of acrylamide level and DE was calculated according to the following 
formula (Sirot et al., 2012):

$$
\mathrm{DE}_{i \mathrm{k}-1}^{\mathrm{n}}=\sum\left(\frac{\mathrm{I}_{i \hbar}, \mathrm{C}_{\mathrm{k}}}{1000, B W_{p} 7}\right)
$$

where $\mathrm{DE} i$ is the total daily exposure to acrylamide of the subject $i$ (g/kg pc/day), $\mathrm{I}_{i k}$ is the weekly intake of the food item $\mathrm{k}$ by the subject $\mathrm{i}$ (g/week), $\mathrm{C}_{\mathrm{k}}$ is the acrylamide concentration of the food item $\mathrm{k}(\mathrm{g} / \mathrm{kg}$ of fresh weight), $\mathrm{BW}_{i}$ is the individual body weight of the subject $\mathrm{i}(\mathrm{kg}), \mathrm{n}$ is the total number of food items consumed by the subject $\mathrm{i}$ among the analyzed foods. The weekly exposure (based on 7 days of food consumption) was divided by a factor 1000 to convert contamination data in $\mu \mathrm{g}$ of acrylamide per gram of food and by a factor 7 to express exposure per day. Mean exposure and $\mathrm{P}^{\text {th }}$ were compared with BMDL by calculating the corresponding MOE for the risk evaluation.

\section{Results and Discussion}

Street food is an important source of meals for young people, especially University's students; the types of foods consumed in Italy are mainly bakery products such as pizza and sandwiches. Table 1 summarizes the consumption of the food categories used in the calculations differentiating the consumption data between boys and girls. Based on the selection performed by tested population among street food, pizza is the more consumed food category in general without considering the gender, followed by stuffed sandwich and hamburgers. The less consumed street food is stuffed thin flatbread. Considering the gender stuffed sandwich is the most consumed followed by pizza and hamburger by the boys; the females reported to consume mainly pizza followed by stuffed sandwich and chicken cuttled sandwiches; in both gender the less consumed food category is stuffed thin flatbread.

The acrylamide content in 10 selected food groups are reported in Table 2. The highest mean acrylamide concentration was found in French fries $(724 \mu \mathrm{g} / \mathrm{kg})$ followed by McDonald's menu ( $459.5 \mu \mathrm{g} / \mathrm{kg})$, chicken cuttled sandwich $(273 \mu \mathrm{g} / \mathrm{kg})$, pizza $(250$ $\mu \mathrm{g} / \mathrm{kg})$ and flat bread $(230 \mu \mathrm{g} / \mathrm{kg})$. In the other food categories the acrylamide content is around $100 \mu \mathrm{g} / \mathrm{kg}$. Folded pizza presented the lowest concentration of acrylamide ( 90 $\mu \mathrm{g} / \mathrm{kg}$ ). All respondents of the study were exposed to acrylamide through the diet; although consumption data showed few
Table 1. Average food consumption of targeted population.

\begin{tabular}{lccc} 
Food item & All & Food consumption (g/day) & Girls \\
\hline Pizza & 27.02 & 26.95 & 27.08 \\
Stuffed stone baked pizza & 7.41 & 8.48 & 6.35 \\
\hline Stuffed thin flatbread & 4.75 & 4.76 & 4.75 \\
Folded pizza & 6.75 & 7.03 & 6.48 \\
\hline Flat bread & 7.75 & 9.42 & 6.08 \\
French fries & 8.23 & 8.26 & 8.20 \\
\hline Hamburgers & 13.81 & 16.70 & 10.91 \\
Stuffed sandwich & 19.55 & 27.46 & 11.64 \\
\hline McDonald's menu & 9.32 & 10.04 & 8.60 \\
Chicken cuttled sandwich & 9.71 & 8.04 & 11.38 \\
\hline
\end{tabular}

Table 2. Estimation of the mean level of acrylamide ( $\mu \mathrm{g} / \mathrm{kg}$ fresh weight) in food groups.

\begin{tabular}{lccc} 
Food sample & N & Acrylamide level $(\boldsymbol{\mu g} / \mathrm{kg})$ & Source \\
Pizza & 12 & 250 & Analyzed \\
Stuffed stone baked pizza & 3 & 99 & Analyzed \\
\hline Stuffed thin flatbread & 8 & 122 & Analyzed \\
Folded pizza & 11 & 90 & Analyzed \\
\hline Flat bread & 8 & 230 & Analyzed \\
French fries & 22 & 724 & Analyzed \\
\hline Hamburgers* & - & 127 & Tateo et al. $(2007)$ \\
Stuffed sandwich & 8 & 111 & Analyzed \\
\hline McDonald's menu* & - & 459 & Tateo et al. $(2007)$ \\
Chicken cuttled sandwich & 4 & 273 & Analyzed \\
\hline
\end{tabular}

*Data of acrylamide content in these food items are not directly analyzed but collected from literature.

Table 3. Estimation of dietary exposure (mean, $50^{\text {th }}$ and $95^{\text {th }}$ percentile) among young population $(\mu \mathrm{g} / \mathrm{kg} \mathrm{bw} /$ day) and contribution $(\%)$ of each food group to the exposure.

\begin{tabular}{lcccc} 
Food item & Mean & $\begin{array}{c}\text { Exposure } \\
\text { P50 }\end{array}$ & $\begin{array}{c}\text { (1/g/kg bw/day) } \\
\text { P95 }\end{array}$ & Contribution \% \\
Pizza & 0.114 & 0.104 & 0.240 & 25.22 \\
Stuffed stone baked pizza & 0.012 & 0.008 & 0.043 & 2.65 \\
\hline Stuffed thin flatbread & 0.010 & 0.005 & 0.032 & 2.21 \\
Folded pizza & 0.010 & 0.000 & 0.046 & 2.21 \\
\hline Flat bread & 0.026 & 0.015 & 0.125 & 5.75 \\
French fries & 0.101 & 0.080 & 0.310 & 22.35 \\
\hline Hamburgers & 0.029 & 0.016 & 0.091 & 6.42 \\
Stuffed sandwich & 0.031 & 0.026 & 0.115 & 6.86 \\
\hline McDonald's menu & 0.070 & 0.063 & 0.301 & 15.49 \\
Chicken cuttled sandwich & 0.049 & 0.031 & 0.236 & 10.84 \\
\hline Total & 0.452 & 0.350 & 1.539 & 100 \\
\hline
\end{tabular}

Table 4. Estimation of the margins of exposure for the mean and $95^{\text {th }}$ percentile of youth dietary exposure to acrylamide.

\begin{tabular}{lcc} 
& Mean & P95 $^{\text {th }}$ \\
Exposure $(\mu / \mathrm{kg}$ bw/day $)$ & 0.452 & 1.539 \\
$\mathrm{MOE}_{\left(\mathrm{BMDL}_{10}=0.17 \mathrm{mg} / \mathrm{kg} \text { bw/day }\right)^{*}}$ & 376.11 & 110.46 \\
\hline $\mathrm{MOE}_{\left(\mathrm{BMDL}_{10}=0.43 \mathrm{mg} / \mathrm{kg} \text { bw/day }\right)^{* *}}$ & 951.33 & 279.40 \\
\hline
\end{tabular}

MOEs, margins of exposure; $\mathrm{BMDL}_{10}$, lower limit on the benchmark dose for a $10 \%$ response. ${ }^{*} \mathrm{BMDL}_{10}$ defined for neoplastic effects (EFSA, $2015)$; ${ }^{*} \mathrm{BMDL}_{10}$ defined for peripheral neuropathy (EFSA, 2015). 
differences between boys and girls no difference were recorded in total acrylamide exposure between genders $(0.411 \pm 0.23$ $\mu \mathrm{g} / \mathrm{kg}$ bw/day and $0.472 \pm 0.22 \mu \mathrm{g} / \mathrm{kg}$ bw/day respectively) therefore data was put together for further evaluations. Mean acrylamide exposure was assessed to be $0.452 \pm 0.21$ $\mu \mathrm{g} / \mathrm{kg}$ bw/day (Table 3).

The $50^{\text {th }}$ percentile was found to be $0.350 \mu \mathrm{g} / \mathrm{kg} \mathrm{bw} /$ day and the $95^{\text {th }}$ was found to be $1.539 \mu \mathrm{g} / \mathrm{kg}$ bw/day. This dietary exposure represents only the exposure from the consumption of street foods during the working/university day. However this intake is similar or even higher than the estimated total daily AA intake in several other countries (El Tawila et al., 2017, Zajac et al., 2013). For example, in a Chinese total diet study, the mean and the $95^{\text {th }}$ percentile dietary intake values were found to be 0.286 and $0.490 \mu \mathrm{g} / \mathrm{kg} \mathrm{bw} /$ day, respectively (Chen et al., 2008). In France, the average dietary intakes have been found to be $0.45 \mu \mathrm{g} / \mathrm{kg}$ bw/day and the $95^{\text {th }}$ percentile values are $1.71 \mu \mathrm{g} / \mathrm{kg}$ bw/day (Sirot et al., 2012). In Canada, the mean and $95^{\text {th }}$ percentile daily intake values are 0.58 and $2.19 \mu \mathrm{g} / \mathrm{kg}$ bw/day, respectively (Normandin et al., 2013). JECFA (2011) has estimated the mean dietary exposure to AA in the general adult population to lie in the range of $0.2-1.0$ $\mu \mathrm{g} / \mathrm{kg} \mathrm{bw} /$ day and the highest intake is estimated to be $0.6-1.8 \mu \mathrm{g} / \mathrm{kg}$ bw/day. The main contributors to the dietary exposure were pizza $(25.22 \%)$ and French fries (22.35\%) followed McDonald's menu (15.49\%) and chicken cuttled sandwich (10.84\%). The lowest contribution is done by stuffed thin flatbread and folded pizza $(2.21 \%)$. Regarding French fries the results are in agreement with those widely reported in literature (JECFA, 2011).

The high contribution of a food category to the daily AA intake can be due to the elevated contamination of the food or to the high food consumption, or the combination of the two factors.

In this study the contribution of French fries is mainly due to the elevated level of contamination of the products, while data on food consumption are lower than those reported by Arisseto et al. (2009) for selected individuals in Brazil (12.53 g/day) and reported by Matthys et al. (2005) for Belgian adolescents (39.88 g/day). Pizza contribution to the AA daily intake is to attribute to the high consumption pattern for Italian young population and to a high AA content. The margins of exposure (MOEs), calculated for the mean exposure to acrylamide, were respectively 376.11 and 951.33 for the $\mathrm{BMDL}_{10}$ considered $(0.17$ and $0.43 \mathrm{mg} / \mathrm{kg}$ bw/day) (Table 4).

For the $95^{\text {th }}$ percentile of exposure the
MOEs ranged 110.46-279.40. Given that AA is a possible genotoxic and carcinogen, the MOE approach may provide an idea of the risks associated with its presence in food. The MOE approach remains the most common method of risk characterization concerning AA despite some uncertainties derived from the use of data from rodents to assess the dose-response curve and from the lack of human external or internal exposure studies to confirm its validity. The obtained MOE values from this study are close to those suggested by the EFSA (50-425) and $\operatorname{JECFA}(45-310)$ to indicate an AA health concern regarding neoplastic effects.

Moreover, the conclusions of the EFSA/WHO, 2005 conference reported that a margin of exposure lower than 10,000, based on a $\mathrm{BMDL}_{10}$ obtained in an animal testing study, represents a public health issue and a need to reduce exposure (EFSA/WHO, 2005). It is therefore advisable to continue efforts in order to reduce dietary exposure to acrylamide.

\section{Conclusions}

The results of this study confirm the general recommendation to the consumer, especially certain population groups, to eat a balanced healthy diet and to limit the amount of baked cereal products and fried products, especially French fries.

\section{References}

Arisseto AP, de Figueiredo Toledo MC, Govaert Y, van Loco J, Fraselle S, Degroodt JM, Caroba, DCR, 2009. Contribution of selected foods to acrylamide intake by a population of Brazilian adolescents. LWT-Food Sci Technol 42:207-11.

Chen F, Yuan Y, Liu J, Zhao G, Hu X, 2008. Survey of acrylamide levels in Chinese foods. Food Addit Contam B 1:85-92.

Delgado-Andrade C, Mesías M, Morales F J, Seiquer I, Navarro MP, 2012. Assessment of acrylamide intake of Spanish boys aged 11-14 years consuming a traditional and balanced diet. LWT-Food Sci Technol 46:16-22.

El Tawila MM, Al-Ansari AM, Alrasheedi AA, Neamatallah AA, 2017. Dietary exposure to acrylamide from cafeteria foods in Jeddah schools and associated risk assessment. J Sci Food Agric (in press).

EFSA, 2006. EFSA/WHO International Conference with support of ILSI Europe on Risk Assessment of Compounds that are both Genotoxic and Carcinogenic. EFSA
Supporting Publications, Parma, Italy.

EFSA, 2015. Scientific Opinion on Acrylamide in food. EFSA J 13:4104.

Haouet N, Pistolese S, Branciari R, Ranucci D, Altissimi MS, 2016. Study of acrylamide level in food from vending machines. Ital J Food Safety 5:191-3.

IARC, 1994. Some industrial chemicals. International Agency for Research on Cancer, Lyon, France. Available from: http://monographs.iarc.fr/ENG/Monograph s/vol60/mono60.pdf

Joint FAO/WHO Expert Committee on Food Additives (JECFA), 2011. Evaluation of certain contaminants in food. (Seventythird report of the Joint FAO/WHO Expert Committee on Food Additives). WHO Technical Report Series, No. 960. JECFA, Rome, Italy.

Matthys C, Bilau M, Govaert Y, Moons E, De Henauw S, Willems JL, 2005. Risk assessment of dietary acrylamide intake in Flemish adolescents. Food Chem Toxicol 43:271-8.

Mesías M, Morales FJ, 2016. Acrylamide in coffee: Estimation of exposure from vending machines. J Food Comp Anal 48:8-12.

Mills C, Mottram DS, Wedzicha BL 2009. Acrylamide. In: R.H. Stadler and D.R. Lineback (eds.) Process-induced food toxicants: occurrence, formation, mitigation, and health risks. John Wiley \& Sons, Inc., Hoboken, NJ, USA, pp 23-50.

Normandin L, Bouchard M, Ayotte P, Blanchet C, Becalski A, Bonvalot Y, Phaneuf D, Lapointe C, Gagné M, Courteau M, 2013. Dietary exposure to acrylamide in adolescents from a Canadian urban center. Food Chem Toxicol 57:75-83.

Pacetti D, Gil E, Frega NG, Álvarez L, Dueñas P, Garzón A, Lucci P, 2015. Acrylamide levels in selected Colombian foods. Food Addit Contam B 8:99-105.

Proietti I, Frazzoli C, Mantovani A, 2014. Identification and management of toxicological hazards of street foods in developing countries. Food Chem Toxicol 63:143-52.

Sirot V, Hommet F, Tard A, Leblanc JC, 2012. Dietary acrylamide exposure of the French population: Results of the second French Total Diet Study. Food Chem Toxicol 50:889-94.

Tateo F, Bononi M, Andreoli G, 2007. Acrylamide levels in cooked rice, tomato sauces and some fast food on the Italian market. J Food Comp Anal 20:232-5.

Zajac J, Bojar I, Helbin J, Kolarzyk E, Potocki A, Strzemecka J, Owoc A, 2013. Dietary acrylamide exposure in chosen population of South Poland. Ann Agric Environl Med 20:351-5. 